\title{
Measuring the Efficiency of Public Hospitals in Kuwait: A Two-Stage Data Envelopment Analysis and a Qualitative Survey Study
}

\author{
Abdullah M. Alsabah ${ }^{1,2}$, Hassan Haghparast-Bidgoli ${ }^{1}$ \& Jolene Skordis ${ }^{1}$ \\ ${ }^{1}$ Institute for Global Health, University College London (UCL), London, UK \\ ${ }^{2}$ Medical Services Authority, Ministry of Defense, Kuwait \\ Correspondence: Abdullah M. Alsabah, Mesillah, Block 7 Street number 6, House number 45 Kuwait, 22001. Tel: \\ 965-97-887-775. E-mail: abdullah.alsabah.14@ucl.ac.uk
}

Received: October 22, 2019 Accepted: February 10, 2020 Online Published: February 24, 2020

doi:10.5539/gjhs.v12n3p121 URL: https://doi.org/10.5539/gjhs.v12n3p121

\begin{abstract}
The recent drop in oil prices has challenged public sector financing in Kuwait. Technical and scale efficiency scores for fifteen public hospitals in Kuwait from 2010 to 2014 were estimated using a two-stage data envelopment analysis (DEA). Technical efficiency scores were regressed against institutional characteristics using Tobit regression to investigate the determinants of efficiency differences in hospitals. Semi-structured interviews were also carried out with fourteen public and private hospital managers to qualitatively explore their perceptions and experience about about factors affecting hospital efficiency.

The mean technical efficiency score for all hospitals was $85.8 \%$, an improvement of $2 \%$ since 2010 . The mean pure technical efficiency score was $79.6 \%$, improving from $75 \%$ in 2010 to $81.2 \%$ in 2014 . The mean scale efficiency score was $91.8 \%$, improving from $87.6 \%$ in 2010 to $94.2 \%$ in 2014 . Only three hospitals were constantly technically and scale efficient. Tobit regression showed that hospital efficiency was significantly associated with the average length of patient stay. Hospitals with more than 400 beds were potentially more technically and scale efficient. The qualitative study revealed that external factors affecting efficiency commonly included implemention of legislative changes and decreasing bureaucracy, while internal factors included increasing bed capacity and improving qualifications and training of human resources.

Most public hospitals in Kuwait were not technically and scale efficient, but improvements were observed. Potential factors that affected the efficiency of hospitals in Kuwait were identified. These findings are useful to decision-makers in Kuwait for developing strategies to improve public hospital efficiency.
\end{abstract}

Keywords: technical efficiency, scale efficiency, data envelopment analysis, public hospitals, Kuwait

\section{Introduction}

In 1962, the Constitution of the State of Kuwait was implemented, which included Articles 11 and 15 ensuring health provision (Sabah, 1962). In accordance with the above-mentioned articles, a 'Health for All' policy was adopted by the government to provide access to comprehensive and high-level quality health services by all (Ministry of Health [MOH], 2016).

Currently, the country's economy is experiencing a decline caused by a drop in oil export returns (Fund, 2016), the main source of healthcare financing. In addition, a rapid increase in health expenditure in the country, due to increased demand for services, has made the situation more challenging ( $\mathrm{MOH}, 2016)$. The increase in healthcare demand has been attributed to multiple factors, including an increase in the total population in the country from about 1.6 million in 1995 to 4.1 million in 2017, as well as an increase in the total life expectancy at birth from 72.7 to 74.8 for the same years (Databank, 2019). Additionally, the increase in demand for advanced services is believed to be the result of the growing health awareness in the population (MOH, 2016).

In response to these challenges, the government of Kuwait issued a six-point economic reform policy document in March 2016 that included 'boosting the public sector's efficiency' and 'launching administrative and institutional reforms by means of upgrading the efficiency of general and financial administration' (Kuwait News Agency [KUNA], 2016).

Providing sustainable health care financing is a challenge for many countries facing increasing demand for 
healthcare services and cost inflation of these services (Osmani, 2012). Since hospitals consume a large portion of the health care budget and are large health-production facilities that have diverse resource inputs, such as buildings, health and administrative personnel, drugs, and equipment, the focus of health decision-makers is often drawn to the efficiency of these facilities to rationally distribute human and capital resources (Chisholm \& Evans, 2010; Osmani, 2012; Oxley \& MacFarlan, 1994; Sefiddashti et al., 2016; Zhou, Xu, Antwi, \& Wang, 2017). Many researchers have evaluated the technical efficiency of hospitals in Europe (Hollingsworth \& Parkin, 1995; Kounetas \& Papathanassopoulos, 2013; Lindlbauer, Schreyögg, \& Winter, 2016; Magnussen, 1996; Pérez-Romero, Ortega-Díaz, Ocaña-Riola, \& Martín-Martín, 2019; Siciliani, 2006; Staat, 2006; Tynkkynen \& Vrangbæk , 2018; Xenos, Nektarios, Constantopuolos, \& Y fantopuolos, 2016), North America (Brown III \& Pagán, 2006; Giménez, Keith, \& Prior, 2019; Harrison, Coppola, \& Wakefield, 2004; Johnson, \& C.Y. Lee, 2016), Asia (Ahmad Kiadaliri, Zarei, \& Haghparast-Bidgoli, 2011; Ahmed et al., 2019a; Ahmed et al., 2019b; Chai, Zhang, Zhou, Liu, Kinfu, 2019; Cheng et al., 2015; Cheng et al., 2016; Guven-Uslu \& Linh, 2008; Hu, Qi, \& Yang, 2012; W.F. Lee \& Wang, 2004; Mahate, Hamidi, \& Akinci, 2016; Osmani, 2012; Cheng et al., 2015; Guven-Uslu \& Linh, 2008; Hu, Qi, \& Yang, 2012; W. F. Lee \& Wang, 2004; Mahate, Hamidi, \& Akinci, 2016; Osmani, 2012), and Africa (Kirigia, Emrouznejad, Sambo, Munguti, \& Liambila, 2004; Kirigia et al., 2010; Masiye, 2007; Mujasi, Asbu, \& Puig-Junoy, 2016; Top, Konca, \& Sapaz, 2019; Zere et al., 2006). A meta-analysis of hospital efficiencies is available for the gulf region (Alatawi, A., Ahmed, S., Niessen, L., \& Khan. J., 2019), but relatively few studies are available that specifically measure the efficiency of public health care and the cost associated with its inefficiencies of Kuwait (Burney et al., 1999; ).

This study aims to measure the technical and scale efficiencies of secondary and tertiary public hospitals in Kuwait for the period 2010 to 2014, using a data envelopment analysis (DEA) approach. This study also aims to identify the factors affecting the efficiency of hospitals. It is believed that this study will provide decision makers in the Kuwaiti health sector with useful information to develop strategies for improving public hospital efficiency.

\section{Methods}

\subsection{Study Setting}

In Kuwait, the share of total health expenditure from gross domestic product (GDP) has increased from $2.5 \%$ in 2000 to $3.9 \%$ in 2016 and public health expenditure as percentage of total government expenditure increased from $5.2 \%$ in 2000 to $6.2 \%$ in 2016 (Databank, 2019). But a substantial change was apparent in the increase in the per capita health expenditure, which increased from $\$ 462.6$ per capita in 2000 to $\$ 1,068.3$ per capita in 2016. In the fiscal year 2011-2012, total health expenditure was around 1.8 billion Kuwaiti Dinars (KD) (around USD\$5.9 billion). In that period, government expenditure on health made up $82 \%$ of the total health expenditure, while out-of-pocket was $16 \%$ of the total health expenditure in the country $(\mathrm{MOH}, 2016)$. More recently, public health expenditure made up $83.9 \%$ of total health expenditure in 2016, making the State the biggest healthcare provider in the country (Databank, 2019).

Health services provided by the Ministry of Health (MOH) are divided into three main levels: primary, secondary and tertiary care. In addition to these, the $\mathrm{MOH}$ also provides other services such as dental health, occupational medicine, preventative medicine, treatment abroad and services during the Hajj season (MOH, 2016). Figure 1 shows describes $\mathrm{MoH}$ spending.

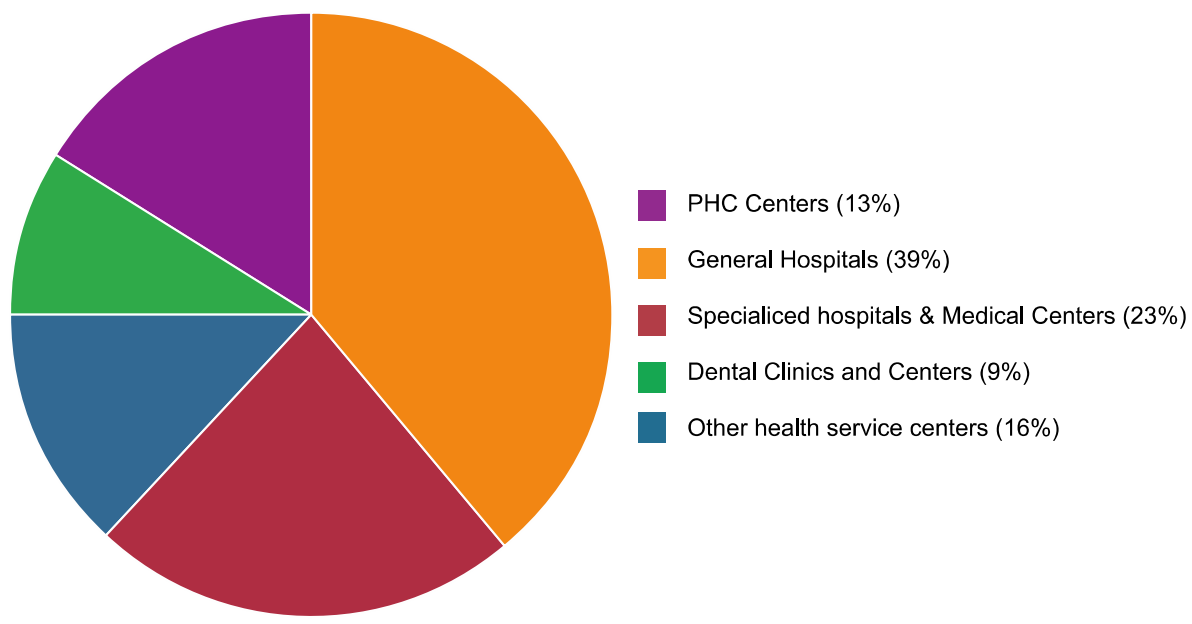

Figure 1. Share of MOH expenditure based on the service provider for the fiscal year 2011-2012 (MOH, 2016) 
As shown in Figure 1, more than $60 \%$ of $\mathrm{MoH}$ resources are consumed by secondary and tertiary healthcare providers. Secondary healthcare providers consist of six general hospitals with outpatient, inpatient and emergency departments. Each of these hospitals provides medical services to the people living in the governorate that these facilities serve.

\subsection{Efficiency Concepts}

Palmer \& Torgerson (1999) explain that efficiency in a health system is associated with the connection between system inputs (proxies of cost such as capital, labour or equipment) and either intermediate outputs (numbers of treated individuals, waiting time, etc.) or final health outcomes (quality adjusted life years (QALYs) or life years gained). In the health system literature, two main types of efficiency are widely mentioned: technical and allocative efficiency. Technical efficiency aims at either maintaining the same level of outputs with less inputs, or more output with the same level of inputs (Bevan, Helderman, \& Wilsford, 2010). Whereas allocative efficiency is believed to be achieved by directing health funds towards interventions that would optimize health gains (Kruk \& Freedman, 2008).

Farrell (1957) explains that a hospital is technically efficient if it was producing a certain level of outputs with the least inputs, or if it was producing the maximum level of outputs with a certain level of inputs, and this efficiency concept is the base of the current study. Mangusson (1996) argued that evaluating the technical efficiency of hospitals allows the comparison of their real use of inputs and outputs rather than costs and 'profits'. It is believed that hospitals' outputs must be clearly identified in order to measure their efficiency. Potential outputs can be number of outpatient visits, number of surgical interventions, number of patient-days, bed turnover and bed occupancy, among others (Moshiri, Aljunid, \& Amin, 2010).

\subsection{Data Envelope Analysis (DEA)}

DEA is the most frequently used technique for measuring the efficiency of a health system as a whole, or of smaller units within a health system such as hospitals (Gok \& Sezen, 2013, O’Neill, Rauner, Heidenberger, \& Kraus, 2008, Pelone et al., 2014). It is a non-parametric approach that uses a linear programming technique for analysing the relative efficiencies of individual Decision-Making Units (DMUs) with respect to multiple inputs and outputs (Roh, Jae Moon, \& Jung, 2013).

DEA has several benefits, including its capacity to measure technical efficiency (Jacobs, 2001). It is also characterised by its ability to deal with multiple outputs and multiple inputs easily (Hollingsworth, Dawson, \& Maniadakis, 1999; Li \& Dong, 2015; O'Neill et al., 2008; Rosko, 2001; Wranik, 2012), even if they were heterogeneous (Osmani, 2012). Additionally, it has the advantage of the simplicity underlying this approach in terms of not having prior or complicated standard assumptions as is the case with statistical regression analysis (Alexander, Busch, \& Stringer, 2003, Hollingsworth et al., 1999, Osmani, 2012). Additionally, it can provide useful information for developing strategies to eliminate areas of inefficiency (Rosko, 2001).

DEA does also have disadvantages. It cannot take into account socioeconomic and environmental factors when measuring technical efficiency of DMUs (S. Hadad, Y. Hadad, \& Simon-Tuval, 2013; Smith \& Street, 2005), and can only analyse the efficiency of homogeneous units (Rosko, 2001). Additionally, it is desirable to have a large sample when applying this method because it is sensitive to sample size (Hadad et al., 2013; Masiye, 2007). The inability to differentiate true inefficiency from random variation is another disadvantage of DEA (Hollingsworth \& Wildman, 2002; Rosko, 2001; Wranik, 2012). This approach also has sensitivity to high-performing outliers, so the efficiency frontier may change if such outliers were not detected (Allin, Grignon, \& Wang., 2015).

Using the CCR model (Charnes, Cooper, \& Rhodes, 1978), multiple output and input variables are incorporated to measure technical efficiency of a DMU in relation to other DMUs (Kirigia, Emrouznejad, \& Sambo, 2002). The calculated relative hospital efficiency scores fall between 0 , completely inefficient, and 1 , being completely efficient. There are two programming models to calculate technical efficiency, under the assumption of constant returns to scale (CRS in model 1) and variable returns to scale (VRS in model 2) (Kirigia et al., 2002).

The model used in this study is an input-oriented model, which was developed by Banker and colleagues (Banker, Charnes, \& Cooper, 1984), where an inefficient unit is made efficient through the proportional reduction of its inputs while its output proportions are held constant. It is possible, by using this model, to assess whether a hospital is producing on an optimal scale, which is known as scale efficiency (Ahmadkiadaliri, Zarei, \& Haghparast-Bidgoli, 2011; Kirigia et al., 2002). This model allows for the division of total technical efficiency (CRS) to pure technical efficiency (VRS) and scale efficiency (Ahmadkiadaliri et al., 2011). According to Coelli (1996) the scale efficiency score is equal to the CRS technical efficiency (TE) score divided by the VRS technical efficiency (TE) score. The degree to which a hospital is producing at an optimal scale is, on the other hand, known 
as scale efficiency (Ahmadkiadaliri et al., 2011). Technical efficiency that is not attributable to departures from optimal scale and is related to operation is known as pure technical efficiency or managerial efficiency (Ahmadkiadaliri et al., 2011). It is believed that hospital managers have more control in altering the level of inputs rather than outputs, and this is one of the justifications for choosing the input-oriented model (Ahmadkiadaliri et al., 2011; Ketabi, 2011).

Model 1. DEA weights model,

Model 2. DEA weights model, input-oriented, CRS input-oriented, VRS

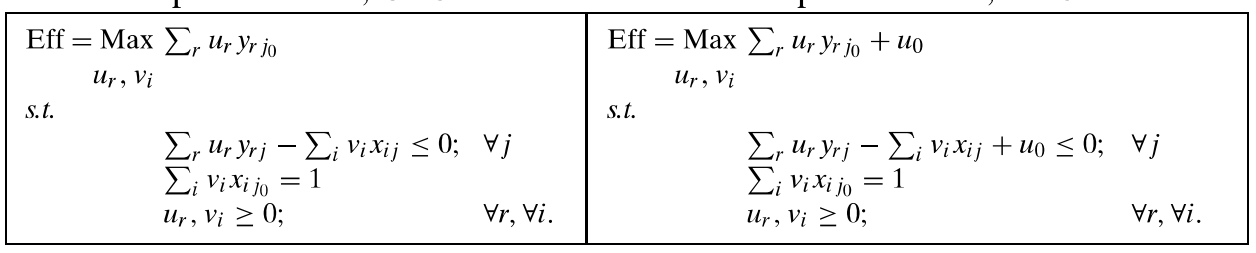

Where (Kirigia et al., 2002)

$Y r j=$ the amount of output $r$ produced by hospital $j$,

$x i j=$ the amount of input $i$ used by hospital $j$,

$u r=$ the weight given to output $r,(r=1, \ldots, t$ and $t$ is the number of outputs $)$

$v_{i}=$ the weight given to output $i,(i=1, \ldots, m$ and $m$ is the number of outputs $)$

$n=$ the number of hospitals,

$j 0=$ the hospital under assessment

\subsection{Two-stage DEA Analysis}

In order to identify the potential factors affecting the technical efficiency of the hospitals, a second stage was added to this study. In this second stage, a regression analysis was performed, in which hospital efficiency scores from the first stage were used as dependent variables and a number of institutional factors were used as independent variables. Independent variables were selected on the basis of literature review, the context of the study and availability of data. The efficiency scores calculated in the first stage were regressed against these variables using Tobit regression analysis. This analysis model, known as censor regression, is widely used in two-stage DEA since the scores have only a positive probability of attaining one of the two corner values (between 0 and 1), and is believed to be sufficient in regressing efficiency cores against exogenous variables (Hoff, 2007). Both stages of the DEA analyses were conducted using Stata version 14 (StataCorp, College Station, Texas 77845 USA).

\subsection{Data and Variables}

The data for this study was obtained from the 'Health, Kuwait' annual report published by the MOH's Department of Statistics. The analysis will include data from 2010 to 2014 relating to a total of fifteen hospitals; six general hospitals at the secondary level and nine specialized hospitals at the tertiary level. The Center for Palliative Care and the Urology Center were not included in the analysis due to a lack of data for the study period. Additionally, some specialized centers were excluded from the sample because they only provide outpatient services and were therefore not comparable DMUs.

Based on the use of similar variables in other studies (Akazili, Adjuik, Jehu-Appiah, \& Zere, 2008; Guven-Uslu \& Linh, 2008; W.F. Lee \& Wang, 2004; O’Neill et al., 2008; Worthington, 2004; Zere et al., 2006) and the availability of local data, four input- and two output-variables were selected for the first stage DEA. Input variables included the number of beds (which is usually used as a proxy for capital inputs in hospital efficiency studies (Kounetas \& Papathanassopoulos, 2013; Worthington, 2004)) and three human resources inputs including total number of doctors, nurses, and non- medical workers. Output variables were total outpatient visits and total number of discharges (a proxy for admissions).

Hospital size (i.e. total number of beds), bed occupancy rate, average length of stay and hospital type (general or specialised) were the independent variables used in the second stage of the analysis. The institutional variables were chosen based on the data availability and the evidence from the previous studies (Cheng et al., 2015; Kounetas \& Papathanassopoulos, 2013; K.S. Lee, Chun, \& J.S. Lee, 2008; W.F. Lee \& Wang, 2004; Osmani, 2012).

\subsection{Semi-Structured Interviews}

To better understand potential factors affecting hospital efficiency in Kuwait, qualitative semi- structured 
interviews were conducted with 14 hospital managers from the public and private sectors. Participants received information sheets that explained the objectives of the study, and provided written informed consent to participate. They were asked open-ended questions about the meaning of hospital efficiency; factors they believe would affect hospital efficiency; and the steps they would take to improve the efficiency of their hospitals. The data were analysed using thematic analysis to identify overall themes and patterns.

\section{Results}

\subsection{Descriptive Results}

Table 1 provides a summary statistics of input and output variables of secondary and tertiary level hospitals in Kuwait for the years 2010 to 2014. On average, number of beds, doctors, nurses, non- medical workers, outpatient clinics visits, and number of discharges for the whole period of the study and for all hospitals were 444, 307, 853, $603,182,057$, and 14,534 respectively.

Table 1. Descriptive statistics of inputs and outputs of secondary and tertiary public hospitals in Kuwait, 2010-2014

\begin{tabular}{|c|c|c|c|c|c|c|c|}
\hline & & Beds & Doctors & Nurses & Non-medical workers & Outpatient visits & Number of discharges \\
\hline \multirow{3}{*}{2010} & Median & 416 & 196 & 656 & 484 & 168944 & 12144 \\
\hline & Mean & 423 & 268 & 800 & 579 & 152992 & 14361 \\
\hline & STDEV & 257 & 205 & 511 & 295 & 99026 & 12715 \\
\hline \multirow{3}{*}{2011} & Median & 418 & 205 & 718 & 501 & 165387 & 12118 \\
\hline & Mean & 447 & 281 & 834 & 590 & 162185 & 14444 \\
\hline & STDEV & 271 & 219 & 522 & 299 & 105728 & 12664 \\
\hline \multirow{3}{*}{2012} & Median & 409 & 219 & 715 & 505 & 160287 & 12087 \\
\hline & Mean & 448 & 297 & 845 & 603 & 166341 & 14405 \\
\hline & STDEV & 270 & 236 & 538 & 310 & 115437 & 12946 \\
\hline \multirow{3}{*}{2013} & Median & 408 & 231 & 729 & 509 & 181270 & 12267 \\
\hline & Mean & 450 & 330 & 852 & 620 & 215564 & 14735 \\
\hline & STDEV & 277 & 274 & 551 & 317 & 158991 & 13399 \\
\hline \multirow{3}{*}{2014} & Median & 418 & 263 & 765 & 503 & 164904 & 12073 \\
\hline & Mean & 453 & 359 & 933 & 622 & 213202 & 14727 \\
\hline & STDEV & 281 & 289 & 605 & 326 & 163647 & 13243 \\
\hline \multirow{3}{*}{ Average } & Median & 414 & 223 & 717 & 500 & 168158 & 12138 \\
\hline & Mean & 444 & 307 & 853 & 603 & 182057 & 14534 \\
\hline & STDEV & 271 & 245 & 545 & 309 & 128566 & 12993 \\
\hline
\end{tabular}


Table 2. Technical and scale efficiency scores for the Kuwait public hospitals, 2010-2014

\begin{tabular}{|c|c|c|c|c|c|c|c|c|c|c|c|c|c|c|c|c|}
\hline \multirow[b]{2}{*}{ Hospital name } & & \multicolumn{3}{|l|}{2010} & \multicolumn{3}{|l|}{2011} & \multicolumn{3}{|l|}{2012} & \multicolumn{3}{|l|}{2013} & \multicolumn{3}{|l|}{2014} \\
\hline & & CRS & VRS & $\begin{array}{l}\text { Scal } \\
\text { e }\end{array}$ & CRS & VRS & $\begin{array}{l}\text { Scal } \\
\text { e }\end{array}$ & CRS & VRS & $\begin{array}{l}\text { Scal } \\
\text { e }\end{array}$ & CRS & VRS & $\begin{array}{l}\text { Scal } \\
\text { e }\end{array}$ & CRS & VRS & $\begin{array}{l}\text { Scal } \\
\text { e }\end{array}$ \\
\hline \multirow{2}{*}{\multicolumn{2}{|c|}{ Sabah }} & 0.79 & 0.83 & 0.95 & 0.81 & 0.84 & 0.96 & 0.75 & 0.78 & 0.95 & 0.78 & 0.79 & 0.98 & 0.78 & 0.86 & 0.90 \\
\hline & & 5 & 2 & 6 & 3 & 5 & 2 & 5 & 8 & 9 & 3 & 5 & 5 & 1 & 0 & 8 \\
\hline \multirow{2}{*}{\multicolumn{2}{|c|}{ Amiri }} & 0.76 & 0.83 & 0.92 & 0.90 & 0.92 & 0.97 & 0.89 & 0.90 & 0.99 & 0.87 & 0.89 & 0.97 & 0.82 & 0.87 & 0.95 \\
\hline & & 7 & 2 & 2 & 1 & 6 & 3 & 8 & 3 & 4 & 3 & 4 & 7 & 9 & 1 & 2 \\
\hline \multirow{2}{*}{\multicolumn{2}{|c|}{ Mubarak Alkabeer }} & 0.75 & 0.83 & 0.90 & 0.86 & 0.89 & 0.96 & 0.84 & 0.90 & 0.92 & 0.81 & 0.85 & 0.95 & 0.77 & 0.80 & 0.96 \\
\hline & & 4 & 2 & 6 & 4 & 2 & 8 & 1 & 9 & 5 & 0 & 0 & 3 & 2 & 4 & 1 \\
\hline \multirow{2}{*}{\multicolumn{2}{|c|}{ Farwaniya }} & 0.99 & 1.00 & 0.99 & 1.00 & 1.00 & 1.00 & 1.00 & 1.00 & 1.00 & 1.00 & 1.00 & 1.00 & 1.00 & 1.00 & 1.00 \\
\hline & & 4 & 0 & 4 & 0 & 0 & 0 & 0 & 0 & 0 & 0 & 0 & 0 & 0 & 0 & 0 \\
\hline \multirow{2}{*}{\multicolumn{2}{|c|}{ Adan }} & 0.91 & 0.96 & 0.95 & 1.00 & 1.00 & 1.00 & 1.00 & 1.00 & 1.00 & 1.00 & 1.00 & 1.00 & 1.00 & 1.00 & 1.00 \\
\hline & & 2 & 0 & 0 & 0 & 0 & 0 & 0 & 0 & 0 & 0 & 0 & 0 & 0 & 0 & 0 \\
\hline \multirow{2}{*}{\multicolumn{2}{|c|}{ Jahra }} & 1.00 & 1.00 & 1.00 & 1.00 & 1.00 & 1.00 & 0.99 & 1.00 & 0.99 & 1.00 & 1.00 & 1.00 & 0.92 & 1.00 & 0.92 \\
\hline & & 0 & 0 & 0 & 0 & 0 & 0 & 1 & 0 & 1 & 0 & 0 & 0 & 9 & 0 & 9 \\
\hline \multirow{2}{*}{ Al-Razi } & & 0.65 & 0.67 & 0.97 & 0.62 & 0.68 & 0.92 & 0.65 & 0.72 & 0.90 & 0.54 & 0.54 & 1.00 & 0.54 & 0.55 & 0.97 \\
\hline & & 7 & 7 & 0 & 8 & 3 & 0 & 4 & 7 & 0 & 3 & 3 & 0 & 3 & 5 & 9 \\
\hline \multirow{2}{*}{$\begin{array}{l}\text { Physical Medicine } \\
\text { Rehabilitation }\end{array}$} & and & 0.32 & 0.69 & 0.46 & 0.26 & 0.68 & 0.39 & 0.36 & 0.85 & 0.42 & 1.00 & 1.00 & 1.00 & 1.00 & 1.00 & 1.00 \\
\hline & & 1 & 6 & 1 & 9 & 6 & 2 & 4 & 4 & 7 & 0 & 0 & 0 & 0 & 0 & 0 \\
\hline \multirow{2}{*}{ Maternity } & & 1.00 & 1.00 & 1.00 & 1.00 & 1.00 & 1.00 & 1.00 & 1.00 & 1.00 & 1.00 & 1.00 & 1.00 & 1.00 & 1.00 & 1.00 \\
\hline & & 0 & 0 & 0 & 0 & 0 & 0 & 0 & 0 & 0 & 0 & 0 & 0 & 0 & 0 & 0 \\
\hline \multirow{2}{*}{\multicolumn{2}{|c|}{ Chest Diseases }} & 0.61 & 0.72 & 0.84 & 0.63 & 0.70 & 0.90 & 0.58 & 0.66 & 0.87 & 0.58 & 0.62 & 0.92 & 0.66 & 0.67 & 0.99 \\
\hline & & 5 & 6 & 7 & 5 & 5 & 0 & 3 & 4 & 8 & 1 & 8 & 6 & 8 & 4 & 2 \\
\hline \multirow{2}{*}{\multicolumn{2}{|c|}{ Infectious Diseases }} & 0.65 & 1.00 & 0.65 & 0.99 & 1.00 & 0.99 & 0.68 & 1.00 & 0.68 & 0.86 & 1.00 & 0.86 & 0.62 & 1.00 & 0.62 \\
\hline & & 9 & 0 & 9 & 4 & 0 & 4 & 3 & 0 & 3 & 4 & 0 & 4 & 6 & 0 & 6 \\
\hline \multirow{2}{*}{\multicolumn{2}{|c|}{ Psychological Medicine }} & 0.41 & 0.55 & 0.74 & 0.51 & 0.59 & 0.86 & 0.54 & 0.66 & 0.80 & 0.53 & 0.63 & 0.84 & 0.60 & 0.62 & 0.96 \\
\hline & & 1 & 2 & 5 & 8 & 8 & 6 & 1 & 9 & 8 & 2 & 0 & 5 & 1 & 5 & 1 \\
\hline \multirow{2}{*}{\multicolumn{2}{|c|}{ Ibn Sina }} & 1.00 & 1.00 & 1.00 & 1.00 & 1.00 & 1.00 & 1.00 & 1.00 & 1.00 & 1.00 & 1.00 & 1.00 & 1.00 & 1.00 & 1.00 \\
\hline & & 0 & 0 & 0 & 0 & 0 & 0 & 0 & 0 & 0 & 0 & 0 & 0 & 0 & 0 & 0 \\
\hline \multirow{2}{*}{\multicolumn{2}{|c|}{ Kuwait Cancer Control Center }} & 0.36 & 0.50 & 0.72 & 0.41 & 0.49 & 0.83 & 0.44 & 0.50 & 0.88 & 0.48 & 0.64 & 0.75 & 0.43 & 0.52 & 0.82 \\
\hline & & 7 & 4 & 8 & 5 & 8 & 3 & 3 & 1 & 4 & 2 & 0 & 4 & 0 & 4 & 0 \\
\hline \multirow{2}{*}{\multicolumn{2}{|c|}{ Kuwait Allergy Center }} & 1.00 & 1.00 & 1.00 & 1.00 & 1.00 & 1.00 & 1.00 & 1.00 & 1.00 & 1.00 & 1.00 & 1.00 & 1.00 & 1.00 & 1.00 \\
\hline & & 0 & 0 & 0 & 0 & 0 & 0 & 0 & 0 & 0 & 0 & 0 & 0 & 0 & 0 & 0 \\
\hline \multirow{2}{*}{ Mean } & & 0.75 & 0.84 & 0.87 & 0.80 & 0.85 & 0.92 & 0.78 & 0.86 & 0.89 & 0.83 & 0.86 & 0.95 & 0.81 & 0.86 & 0.94 \\
\hline & & 0 & 1 & 6 & 2 & 6 & 0 & 4 & 8 & 7 & 1 & 5 & 3 & 2 & 1 & 2 \\
\hline & & 0.76 & 0.83 & 0.95 & 0.90 & 0.92 & 0.97 & 0.84 & 0.90 & 0.95 & 0.87 & 1.00 & 1.00 & 0.82 & 1.00 & 0.97 \\
\hline Ménап & & 7 & 2 & 0 & 1 & 6 & 3 & 1 & 9 & 9 & 3 & 0 & 0 & 9 & 0 & 9 \\
\hline Standard deviation & & 0.24 & 0.17 & 0.16 & 0.25 & 0.17 & 0.16 & 0.23 & 0.16 & 0.16 & 0.2 & 0.17 & 0.08 & 0.2 & 0.18 & 0.1 \\
\hline Coefficient of variation, \% & & 32.2 & 20.7 & 18.3 & 30.9 & 20.4 & 16.9 & 28.8 & 18.7 & 17.7 & 24.1 & 20 & 7.89 & 24.3 & 21 & 10.7 \\
\hline
\end{tabular}

Note. CRS=constant returns to scale technical efficiency (overall technical efficiency); VRS=variable returns to scale technical efficiency (pure technical efficiency); Scale=scale efficiency.

\subsection{First Stage DEA: Efficiency Results}

Table 2 presents the DEA results. Three hospitals (20\%) were constantly technical and scale efficient for the whole period. The mean technical efficiency score was $86 \%$ over the study period, and it improved by $2 \%$ since 2010 . The mean pure technical efficiency score was around $80 \%$, which improved from $75 \%$ in 2010 to $81 \%$ in 2014 . Figure 2. Changes in efficiency scores over the 2010-2014 study period shows the changes of efficiency scores 
during the period 2010-2014.

In 2010, 2011, 2012, 2013 and 2014, out of the 15 hospitals, approximately six (40\%), seven (47\%), seven (47\%), eight (53\%) and eight (53\%) hospitals respectively had a technical efficiency score of 1 (fully efficient). The average pure or managerial technical efficiency (VRS) scores were $84 \%, 86 \%, 87 \%, 87 \%$ and $86 \%$ respectively during the five years under consideration. This finding implies that if the hospitals were operating efficiently, they could have produced $16 \%, 14 \%, 13 \%, 13 \%$ and $14 \%$ more output using their current levels of input, or could produce their current levels of output with $16 \%, 14 \%, 13 \%, 13 \%$ and $14 \%$ reductions in their existing inputs.

The mean scale efficiency score was $92 \%$, which improved from $88 \%$ in 2010 to $94 \%$ in 2014 . Based on the analysis of scale efficiency, it can be illustrated that in period of 2010-1014: four (27\%), six (40\%), five (33\%), eight (53\%) and six (40\%) hospitals displayed constant returns to scale, which means that they were operating at their most productive scale sizes. The average scale efficiency score in the sample was $86 \%$ in $2010,92 \%$ in 2011 , $90 \%$ in $2012,95 \%$ in 2013 and $94 \%$ in 2014.

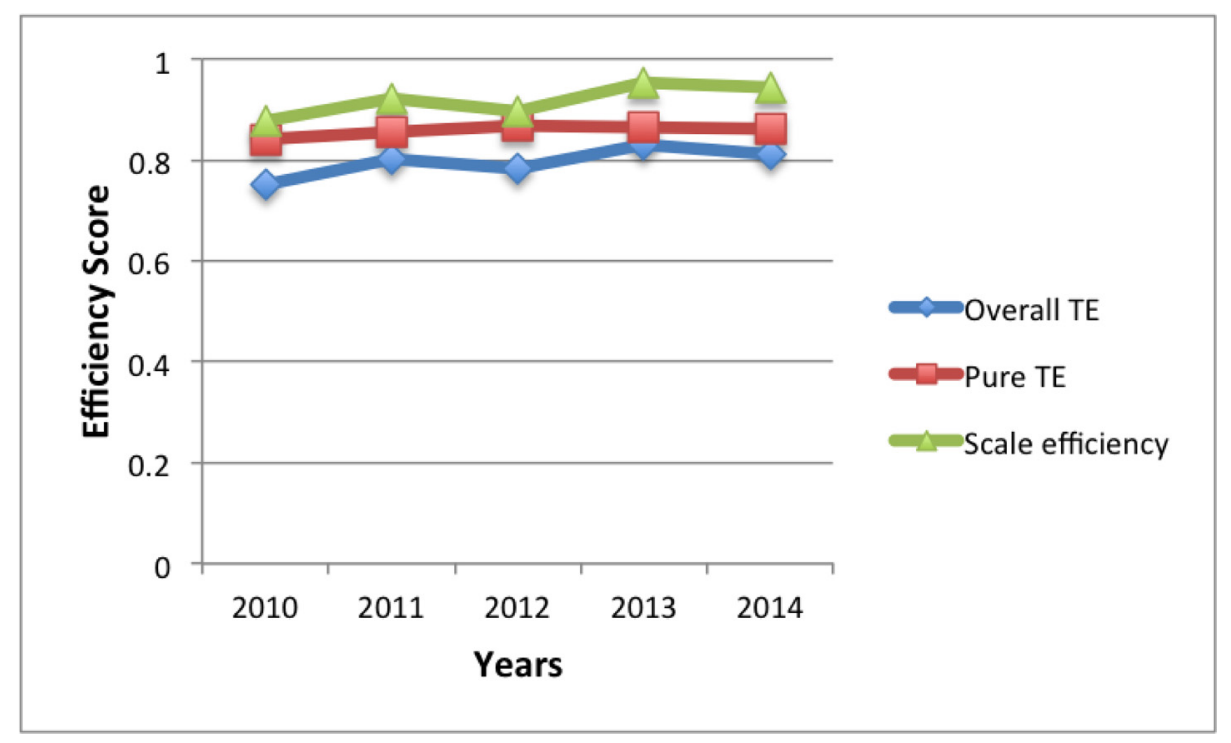

Figure 2. Changes in efficiency scores over the 2010-2014 study period

Hospitals in Kuwait are already operating at a high and increasing level of efficiency but the opportunity for further efficiency gains exists in this context. Table 3 illustrates the total amount of input reductions and/or output increases needed to make less efficient hospitals fully efficient for the years 2010-2014. In 2010, the less efficient hospitals combined had 765 (19.1\%) more doctors than needed to be efficient, which was the largest percentage among all variables in the study. For the same year, hospitals could be more technically efficient if they were able to decrease their input levels by $7.9 \%$ fewer beds, $9.2 \%$ fewer nurses and $5.3 \%$ fewer non-medical workers, while holding their level of outputs constant. Alternatively, an increase of $12.5 \%$ in outpatient visits and $0.3 \%$ in discharges - while keeping inputs constant - would improve efficiency for the same year. In 2014 on the other hand, a reduction of $8.9 \%$ in the number of beds, $9.7 \%$ in the number of doctors, $8.2 \%$ in the number of nurses and $7.1 \%$ in the number of non-medical staff would be required to reach full technically efficiency - while keeping the level of outputs constant. Alternatively, for the same year, the level of output increase required to make hospitals efficient would be $6.2 \%$ in outpatient visits, while utilizing the same level of inputs.

\subsection{Second Stage DEA: Results of Tobit Regression Analysis}

At the second stage of the DEA, technical efficiency scores estimated at the first stage were regressed against a group of hospital level variables, including type of hospital (general or specialized), number of beds, bed occupancy rate and average length of stay, in order to determine the factors affected the technical efficiency of the hospitals. Table 4 shows the results of the regression analysis. The results show that the average length of stay is a significant determinant of hospital technical efficiency; indicating that the higher the average length of stay, the lower overall (CRS) technical efficiency $(\mathrm{p}<0.05)$ and lower scale efficiency $(\mathrm{p}<0.001)$. A higher number of beds was also found to be associated with higher scale efficiency $(\mathrm{p}<0.05)$. 
Table 3. Total input reductions and/or output increases needed to make inefficient hospitals efficient, 2010-2014

\begin{tabular}{|c|c|c|c|c|c|c|c|}
\hline & & Beds & Doctors & Nurses & $\begin{array}{l}\text { Non-medical } \\
\text { workers }\end{array}$ & $\begin{array}{l}\text { Outpatient } \\
\text { visits }\end{array}$ & $\begin{array}{l}\text { Number } \\
\text { discharges }\end{array}$ \\
\hline \multirow{3}{*}{2010} & Total actual values & 6338 & 4014 & 11995 & 8680 & 2294882 & 215417 \\
\hline & Shortfall/excess & 498 & 765 & 1102 & 461 & 287086 & 656 \\
\hline & $\begin{array}{l}\% \text { of total actual } \\
\text { values }\end{array}$ & $7.9 \%$ & $19.1 \%$ & $9.2 \%$ & $5.3 \%$ & $12.5 \%$ & $0.3 \%$ \\
\hline \multirow{3}{*}{2011} & Total actual values & 6703 & 4219 & 12504 & 8850 & 2432773 & 216658 \\
\hline & Shortfall/excess & 631 & 517 & 1047 & 892 & 214941 & 243 \\
\hline & $\begin{array}{l}\% \text { of total actual } \\
\text { values }\end{array}$ & $9.4 \%$ & $12.3 \%$ & $8.4 \%$ & $10.1 \%$ & $8.8 \%$ & $0.1 \%$ \\
\hline \multirow{3}{*}{2012} & Total actual values & 6714 & 4462 & 12676 & 9051 & 2495121 & 216073 \\
\hline & Shortfall/excess & 654 & 572 & 1124 & 957 & 239975 & 1921 \\
\hline & $\begin{array}{l}\% \text { of total actual } \\
\text { values }\end{array}$ & $9.7 \%$ & $12.8 \%$ & $8.9 \%$ & $10.6 \%$ & $9.6 \%$ & $0.9 \%$ \\
\hline \multirow{3}{*}{2013} & Total actual values & 6756 & 4947 & 12786 & 9296 & 3233456 & 221032 \\
\hline & Shortfall/excess & 606 & 520 & 957 & 615 & 237967 & 0 \\
\hline & $\begin{array}{l}\% \text { of total actual } \\
\text { values }\end{array}$ & $9.0 \%$ & $10.5 \%$ & $7.5 \%$ & $6.6 \%$ & $7.4 \%$ & $0.0 \%$ \\
\hline \multirow{3}{*}{2014} & Total actual values & 6793 & 5378 & 14000 & 9327 & 3198023 & 220901 \\
\hline & Shortfall/excess & 602 & 524 & 1151 & 658 & 199824 & 35 \\
\hline & $\begin{array}{l}\% \text { of total actual } \\
\text { values }\end{array}$ & $8.9 \%$ & $9.7 \%$ & $8.2 \%$ & $7.1 \%$ & $6.2 \%$ & $0.0 \%$ \\
\hline
\end{tabular}

Moreover, we explored the relationship between efficiency scores and hospital size, in terms of the number of beds (Figure 3). The results show that larger hospitals (with more than 400 beds) are generally more technically and scale efficient.

\subsection{Qualitative Interviews}

To better understand the potential factors affecting efficiency of the hospital in the context of Kuwait, qualitative semi-structured interviews were conducted with 14 hospital managers from public, private and military sectors. Twenty managers from the public and private sector hospitals in Kuwait were approached to take part in an interview. Six declined and 14 participated. Among the 14 participants, $2(14 \%)$ were female, ten had Kuwaiti nationality (71\%), eight (57\%) were from public hospitals, nine $(64 \%)$ had a postgraduate qualification in health management and nine (64\%) had management experience of 10 years or more. A detailed description of the participants' characteristics is presented in Appendix 1. 
Table 4. Result of Tobit regression analysis

\begin{tabular}{llll}
\hline & $(1)$ & $(2)$ & $(3)$ \\
& CRS TE & VRS TE & Scale \\
\hline Tertiary & -0.0654 & -0.126 & 0.0638 \\
& $(0.0989)$ & $(0.0927)$ & $(0.0543)$ \\
\hline Number of beds & 0.000212 & 0.000152 & $0.000207^{* *}$ \\
& $(0.000180)$ & $(0.000172)$ & $(0.0000970)$ \\
\hline Bed occupancy rate, $\%$ & -0.00161 & $-0.00768^{* *}$ & 0.00168 \\
& $(0.00258)$ & $(0.00291)$ & $(0.00141)$ \\
\hline Average length of stay, days & $-0.00480^{* *}$ & -0.000727 & $-0.00509^{* * *}$ \\
\hline Constant & $(0.00208)$ & $(0.00196)$ & $(0.00114)$ \\
\hline $\mathrm{N}$ & $0.971^{* * *}$ & $1.421^{* * *}$ & $0.807^{* * *}$ \\
Pseudo ${ }^{2}$ & $(0.174)$ & $(0.193)$ & $(0.0949)$ \\
$\chi^{2}$ & 75 & 75 & 75 \\
$\mathrm{p}^{2}$-value & 0.221 & 0.227 & 0.474 \\
\hline
\end{tabular}

Standard errors in parentheses; ${ }^{*} p<0.1,{ }^{* *} p<0.05,{ }^{* * *} p<0.01$

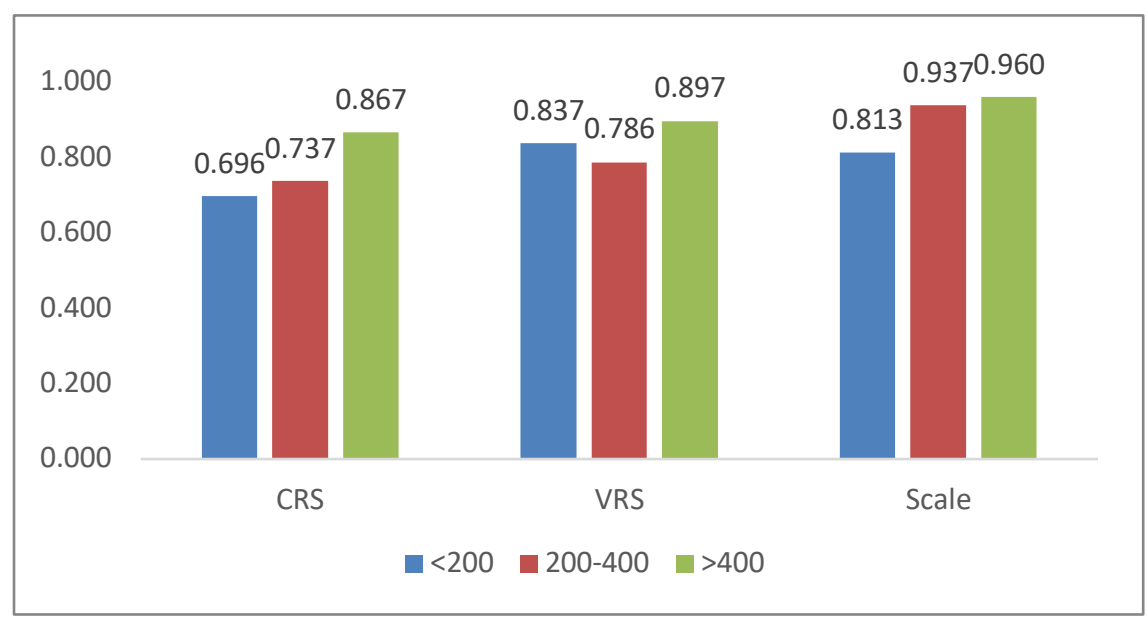

Figure 3. Relationship between efficiency scores and the number of hospital beds

Participants expressed their perception of factors affecting the efficiency of their hospitals as well as factors that would help in improving hospital efficiency. The factors reported by participants can be grouped into two broad categories: External and internal factors. External factors include the presence of a national strategic health plan, legislative changes, bureaucracy in the system, provider payment mechanisms (mainly salary), and communications between hospitals. Managers stated that bureaucracy lead to a slow and centralised process of decision making. This is believed to be due to the rigid structure of the public healthcare sector, the lack of autonomy for hospital managers, and that decision makers at high levels in the ministry are overwhelmed. Internal factors include bed capacity, qualifications and training of human resources, procurement and utilisation of equipment, the use health information system (HIS), as well as the accountability of staff and users.

\section{Discussion}

The literature suggests that a common cause of technical inefficiency is the sub-optimal or unnecessary use of certain resources such as excessive hospitalization (Chisholm \& Evans, 2010). Other causes of technical 
inefficiency include overstaffing and weak purchasing or distribution systems (Mills, 1995; Tandon, Lauer, Evans, \& Murray, 2003). Another example of inefficiencies found in hospitals is the under-utilisation of services (e.g. low utilisation of beds), which may be observed when hospitals show diseconomies of scale when they depart from their optimal level of efficiency by deciding to enlarge (Chisholm \& Evans, 2010).

This study measured the technical efficiency of secondary and tertiary public hospitals in Kuwait. It was found that three hospitals $(20 \%)$ were constantly technical and scale efficient, and therefore $80 \%$ of hospitals could have made efficiency gains during the study period. The percentage of less efficient hospitals in this study is high when compared to a study of the efficiency of general hospitals in South of Iran, which found that $53 \%$ of hospitals were technically inefficient (Kiadaliri et al., 2011). Mahate and colleagues (2016) found that one third of hospitals in the United Arab Emirates were technically efficient. Studies conducted in two settings in Sub-Saharan Africa showed that $74 \%$ of hospitals in Kenya (Kirigia et al., 2002), and $40 \%$ of hospitals in Zambia were technically efficient (Masiye, 2007).

The results from this study are comparable with earlier work (Burney, Mohammad, \& Al-Ramadhan, 1999), which assessed the cost of inefficiencies in the public health care system in Kuwait. These authors concluded that there were relative inefficiencies in the production of health services in the country at that time. They believed that an over supply of beds and nurses caused an excess of $18 \%$ in total health expenditure in Kuwait.

As explained in other studies, in order to decrease the inefficiencies in hospitals, there should be close evaluation of the excess in medical and non-medical manpower (Osmani, 2012). The results of this study showed that a hospital's size has an effect on its efficiency, which was supported by other studies (W.F. Lee \& Wang, 2004; Masiye, 2007; Worthington, 2004). It was found that the larger hospitals were potentially more technically and scale efficient. This is in line with the findings of studies conducted in the South of Iran (Kiadaliri, Zarei, \& Haghparast-Bidgoli, 2011) and in Thailand (Watcharasriroj \& Tang, 2004).

The results of the Tobit regression revealed that the average length of stay was significantly associated with overall technical efficiency of the hospitals. Previous studies (Cheng et al., 2015; Herr, 2008) have found similar results where there was a negative association between the average length of stay and technical efficiency. There was no statistically significant association between technical efficiency with other institutional factors such as bed occupancy rate and level of specialisation. This was not the case in previous studies. For example, K.S. Lee and colleagues (2008) found that hospitals that were more specialised, were also more efficient. Moreover, Kounetas and Papathanassopoulos (2013) described that the hospital type (Regional, Prefectural, or University) affected the technical efficiency of hospitals in Greece.

Other factors that were believed to affect hospital efficiency were explored through semi-structured interviews with hospital managers in the country. Managers believed that there were external factors, such as changes in regulations, financing/provider payment mechanisms, and centralization (i.e. less autonomy for hospitals), which affected efficiency of the hospitals. Dalmau-Atarrodona and Puig-Junoy (1998) showed that healthcare regulations as well as the presence of competitors would affect hospital efficiency scores. Alternatively, Tiemann and Schreyögg (2012) argued that resources were used more efficiently after converting hospitals to a private for-profit status in Germany, for example. Hu and colleagues (2012) have concluded that there was a negative relationship between government subsidy and hospital's efficiency when they evaluated the effect of a health insurance reform in China. Another study from Norway has shown that the introduction of activity-based financing has improved the technical efficiency of hospitals (Biørn, Hagen, Iversen, \& Magnussen, 2003). Most participants described increasing their autonomy would increase the efficiency of their hospitals, which was supported by studies from other settings (Guven-Uslu \& Linh, 2008). The use of health information systems, on the other hand, was believed to increase the efficiency of a hospital by several participants. This was supported by a study in Thailand, which showed that there was a positive relation between the use of IT and the efficiency of public hospitals (Watcharasriroj \& Tang, 2004). Additionally, the use of technology was found to decrease scale inefficiencies in Greek hospitals (Kounetas \& Papathanassopoulos, 2013).

This study has provided evidence that could be useful to managers and policy makers in formulating reforms to improve the efficiency of public hospitals. The government of Kuwait aims to improve the efficiency of public services in the country, including health services, due to the current economic situation. The technical efficiency as well as factors influencing the efficiency could help health policy makers to make informed decisions to improve the technical efficiency of the main health-producing units in the country. Most hospitals were found to be technically inefficient suggesting that there is room for improvement in this domain. Additionally, any health reform that aims to improve the performance of local health services should take into consideration the factors that were found to influence the technical efficiency of hospitals. Similar studies have emphasised on the importance of 
studying other dimensions of performance, such as quality and equity in addition to efficiency, in order to have a comprehensive picture of the performance of hospitals (Dalmau-Atarrodona \& Puig-Junoy, 1998; Guven-Uslu \& Linh, 2008).

\section{Limitations}

It is important to note that in order to improve future research in this field, the limitations that faced this study should be taken into consideration. Firstly, there were some limitations related to the method that was used in the second stage of this study. Simar and Wilson (2011) argue that tobit regression in the second stage of DEA constitutes a mis-specification. They explain that tobit estimation in the second stage produces biased and inconsistent estimates when compared to their truncated model (Simar \& Wilson, 2011). Secondly, this study was unable to determine to what extent the inefficiency might be caused by quality of care variations due to the lack of data about variables reflecting severity of diseases and quality of care provided in hospitals. Just as other researchers recommended, in order to improve quality of future studies measuring hospital efficiency, more efforts need to be made in developing appropriate indicators reflecting quality of care in hospitals (Kiadaliri et al., 2011). Thirdly, when applying DEA, it is desirable to have a large sample size. The sample size for the current study is 15 hospitals, which is the total number of public hospitals that provided inpatient and outpatient services in Kuwait during 2010-2014. Fourthly, the data used in this study is outdated but it was used because of uniformity reasons. Alsabah hospital, which is a secondary level hospital, was divided to two administratively independent hospitals, Alsabah (secondary) hospital and Zain (tertiary) ENT hospital in 2015. This division resulted in a disparity in the variables that were used in the two stages on the analysis. Additionally, the allergy center, which was one of the efficient hospitals throughout the study period, stopped providing inpatient services starting in the year 2015. So for this hospital, one of the variables that were used in the analysis would be lost. Fifthly, it is desirable to have a homogeneous sample when applying DEA. However, in the current study, six hospitals provided general services whereas nine hospitals provided mainly specialized services in addition to some general services.

\section{Conclusion}

This study has quantified the technical and scale efficiency of 15 public hospitals in Kuwait, and identified the input reductions and/or output increases needed to make inefficient hospitals efficient. The results show that the majority of the public hospitals are not operating at technically efficient levels, indicating room to improve the performance of these hospitals. This study also provided an insight into the factors affecting the efficiency of hospitals. Health policy makers in Kuwait can extract useful information from this study to develop concrete strategies to improve hospital efficiency. Replicating the analyses performed in this study on a routine basis for public healthcare facilities would help in identifying ways of best practice, but this would not be easy to achieve unless timely and accurate data is available.

\section{Acknowledgements}

We acknowledge the financial support of the Ministry of Defence in the State of Kuwait. We owe profound gratitude to the National Center for Health Information, Ministry of Health, Kuwait that generously provided data. Special thanks to Eugene Antipov for his assistance with the statistical analysis.

\section{Competing Interests Statement}

The authors declare that there are no competing or potential conflicts of interest.

\section{References}

Ahmad Kiadaliri, A., Zarei, A., \& Haghparast-Bidgoli, H. (2011). Measuring efficiency of general hospitals in the South of Iran. World Applied Sciences Journal, 13, 1310-1316. Retrieved from http://www.idosi.org/wasj/wasj13(6)/4.pdf

Ahmed, S., Hasan, M. Z., Laokri, S., Jannat, Z., Ahmed, M. W., Dorin, F., ... Khan, J. A. M. (2019a). Technical efficiency of public district hospitals in Bangladesh: a data envelopment analysis. Cost Effectiveness and Resource Allocation C/E, 17, 15. https://doi.org/10.1186/s12962-019-0183-6

Ahmed, S., Hasan, Md. Z., MacLennan, M., Dorin, F., Ahmed, M. W., Hasan, Md. M., ... \& Khan, J.A.M. (2019b). Measuring the efficiency of health systems in Asia: a data envelopment analysis. BMJ Open, 9 , e022155. https://doi.org/10.1136/bmjopen-2018-022155

Akazili, J., Adjuik, M., Jehu-Appiah, C., \& Zere, E. (2008). Using data envelopment analysis to measure the extent of technical efficiency of public health centres in Ghana. BMC International Health Human Rights, 8, 1. https://doi.org/10.1186/1472-698X-8-11 
Alatawi, A., Ahmed, S., Niessen, L., \& Khan, J. (2019). Systematic review and meta-analysis of public hospital efficiency studies in Gulf region and selected countries in similar settings. Cost Effective Resource Allocation, 17, 17 https://doi.org/10.1186/s12962-019-0185-4

Alexander, C. A., Busch, G., \& Stringer, K. (2003). Implementing and interpreting a data envelopment analysis model to assess the efficiency of health systems in developing countries. IMA Journal of Management Mathematics, 14, 49-63. https://doi.org/10.1093/imaman/14.1.49

Allin, S., Grignon, M., \& Wang, L. (2015). The determinants of efficiency in the Canadian health care system. Health Economics, Policy and Law, 11, 39-65. https://doi.org/10.1017/S1744133115000274

Apornak, A., Raissi, S., Keramati, A., \& Khalili-Damghani, K. (2020). Optimizing human resource cost of an emergency hospital using multi-objective Bat algorithm. International Journal of Healthcare Management (published online, Jan., 2020). https://doi.org/10.1080/20479700.2019.1707415

Banker, R. D., Charnes, A., \& Cooper, W. W. (1984). Some models for estimating technical and scale inefficiencies in data envelopment analysis. Management Science, 30, 1078-1092. https://doi.org/10.1287/mnsc.30.9.1078

Bevan, G., Helderman, J.-K., \& Wilsford, D. (2010). Changing choices in health care: implications for equity, efficiency and cost. Health Economics, Policy, and Law, 5, 251-67. https://doi.org/10.1017/S1744133110000022

Biørn, E., Hagen, T. P., Iversen, T., \& Magnussen, J. (2003). The effect of activity-based financing on hospital efficiency: a panel data analysis of DEA efficiency scores 1992-2000. Health Care Management Science, 6, 271-283. https://doi.org/10.1023/A:1026212820367

Brown III, H. S., \& Pagán, J. A. (2006). Managed care and the scale efficiency of US hospitals. International Journal of Health Care Finance and Economics, 6, 278-289. https://doi.org/10.1007/s10754-006-9005-4

Burney, N. A., Mohammad, O. E., \& Al-Ramadhan, M. A. (1999). Assessing the cost of inefficiencies: The case of the public health care system in Kuwait. International Social Science Review, 74, 20.

Chai, P., Zhang, Y., Zhou, M., Liu, S., \& Kinfu, Y. (2019). Technical and scale efficiency of provincial health systems in China: a bootstrapping data envelopment analysis. BMJ Open, 9, e027539. https://doi.org/10.1136/bmjopen-2018-027539

Charnes, A., Cooper, W. W., \& Rhodes, E. (1978). Measuring the efficiency of decision making units. European Journal of Operational Research, 2,429-444. https://doi.org/10.1016/0377-2217(78)90138-8

Cheng, Z.-H., Tao, H.-B., Cai, M., Lin, H.-F., Lin, X.-J., Shu, Q., \& Zhang, R.-N. (2015). Using a two-stage data envelopment analysis to estimate the efficiency of county hospitals in China: a panel data study. The Lancet, 386, S64. https://doi.org/10.1016/S0140-6736(15)00645-5

Cheng, Z., Cai, M., Tao, H., He, Z., Lin, X., Lin, H., \& Zuo, Y. (2016). Efficiency and productivity measurement of rural township hospitals in China: a bootstrapping data envelopment analysis. BMJ open, 6(11), e011911. https://doi.org/10.1136/bmjopen-2016-011911

Chisholm, D., \& Evans, D. B. (2010). Improving health system efficiency as a means of moving towards universal coverage. In World health report. Background Paper. Geneva, Switzerland: World Health Organization; 2010.

Coelli, T. (1996). A guide to DEAP version 2.1: a data envelopment analysis (computer) program. Centre for Efficiency and Productivity Analysis, University of New England, Australia.

Dalmau-Atarrodona, E., \& Puig-Junoy, J. (1998). Market structure and hospital efficiency: evaluating potential effects of deregulation in a National Health Service. Review of Industrial Organization, 13, 447-466. https://doi.org/10.1023/A:1007775616593

Databank, T. W. B. (2019). 2019 ed. Washington D.C.: The World Bank Group.

Farrell, M. J. (1957). The measurement of productive efficiency. Journal of the Royal Statistical Society. Series A (General), 120, 253-290. https://doi.org/10.2307/2343100

Fund, I. M. (2016). IMF Country Report No. 17/16: Kuwait.

García-Lacalle, J., \& Martín, E. (2013). Efficiency improvements of public hospitals under a capitation payment scheme. Health Economics, Policy and Law, 8. https://doi.org/10.1017/S1744133112000345 
Giménez, V., Keith, J. R., \& Prior. (2019). Do healthcare financing systems influence hospital efficiency? A metafrontier approach for the case of Mexico. Health Care Management Science, $22,549$. https://doi.org/10.1007/s10729-019-9467-9

Gok, M. S., \& Sezen, B. (2013). Analyzing the ambiguous relationship between efficiency, quality and patient satisfaction in healthcare services: The case of public hospitals in Turkey. Health Policy, 111. https://doi.org/10.1016/j.healthpol.2013.05.010

Guven-Uslu, P., \& Linh, T. P. (2008). Effects of changes in public policy on efficiency and productivity of general hospitals in Vietnam. ESRC Centre for Competition Policy Working Paper. https://doi.org/10.2139/ssrn.1285505

Hadad, S., Hadad, Y., \& Simon-Tuval, T. (2013). Determinants of healthcare system's efficiency in OECD countries. The European Journal of Health Economics, 14, 253-265. https://doi.org/10.1007/s10198-011-0366-3

Harrison, J. P., Coppola, M. N., \& Wakefield, M. (2004). Efficiency of federal hospitals in the United States. Journal of Medical Systems, 28, 411-422. https://doi.org/10.1023/B:JOMS.0000041168.28200.8c

Harrison, J. P., \& Meyer, S. (2014). Measuring Efficiency Among US Federal Hospitals. The Health Care Manager, 33, 117-127. https://doi.org/10.1097/HCM.0000000000000005

Hernandez, A. R., \& San Sebastien, M. (2014). Assessing the technical efficiency of health posts in rural Guatemala: a data envelopment analysis. Global Health Action, 7, 1. https://doi.org/10.3402/gha.v7.23190

Herr, A. (2008). Cost and technical efficiency of German hospitals: does ownership matter? Health Economics, 17, 1057-1071. https://doi.org/10.1002/hec.1388

Hoff, A. (2007). Second stage DEA: Comparison of approaches for modelling the DEA score. European Journal of Operational Research, 181, 425-435. https://doi.org/10.1016/j.ejor.2006.05.019

Hollingsworth, B., Dawson, P. J., \& Maniadakis, N. (1999). Efficiency measurement of health care: A review of non-parametric methods and applications. Health Care Management Science, 2, 161-72. https://doi.org/10.1023/A:1019087828488

Hollingsworth, B., \& Parkin, D. (1995). The efficiency of Scottish acute hospitals: An application of data envelopment analysis. Mathematical Medicine and Biology, 12, 161-173. https://doi.org/10.1093/imammb/12.3-4.161

Hollingsworth, B., \& Parkin, D. (2003). Efficiency and productivity change in the English National Health Service: can data envelopment analysis provide a robust and useful measure? Journal of Health Services Research \& Policy, 8, 230-236. https://doi.org/10.1258/135581903322403308

Hollingsworth, B., \& Wildman, J. (2002). The efficiency of health production: re-estimating the WHO panel data using parametric and nonparametric approaches to provide additional information. Health Economics, 12, 493-504. https://doi.org/10.1002/hec.751

Hu, H.-H., Qi, Q., \& Yang, C.-H. (2012). Analysis of hospital technical efficiency in China: Effect of health insurance reform. China Economic Review, 23, 865-877. https://doi.org/10.1016/j.chieco.2012.04.008

Jacobs, R. (2001). Alternative Methods to Examine Hospital Efficiency: Data Envelopment Analysis and Stochastic Frontier Analysis. Health Care Management Science, 4, 103-115. https://doi.org/10.1023/A:1011453526849

Jehu-Appiah, C., Sekidde, S., Adjuik, M., Akazili, J., Almeida, S. D., Nyonator, F., Baltussen, R., Asbu, E. Z., \& Kirigia, J. M. (2014). Ownership and technical efficiency of hospitals: evidence from Ghana using data envelopment analysis. Cost Effectiveness and Resource Allocation, $12,1$. https://doi.org/10.1186/1478-7547-12-9

Johnson, A. L., \& Lee, C. Y. (2016). Predictive efficiency analysis: A study of us hospitals. In In K. Tone (Ed.) Advances in DEA Theory and Applications: With Examples in Forecasting Models (pp. 404-418). Wiley-Blackwell Online. https://doi.org/10.1002/9781118946688.ch26

Ketabi, S. (2011). Efficiency measurement of cardiac care units of Isfahan hospitals in Iran. Journal of Medical Systems, 35, 143-150. https://doi.org/10.1007/s10916-009-9351-0

Kirigia, J. M., Emrouznejad, A., \& Sambo, L. G. (2002). Measurement of technical efficiency of public hospitals in Kenya: using data envelopment analysis. Journal of Medical Systems, 26, 39-45. 
https://doi.org/10.1023/A:1013090804067

Kirigia, J. M., Emrouznejad, A., Sambo, L. G., Munguti, N., \& Liambila, W. (2004). Using data envelopment analysis to measure the technical efficiency of public health centers in Kenya. Journal of Medical Systems, 28, 155-166. https://doi.org/10.1023/B:JOMS.0000023298.31972.c9

Kirigia, J. M., Mensah, O. A., Mwikisa, C., Asbu, E. Z., Emrouznejad, A., Makoudode, P., \& Hounnankan, A. (2010). Technical efficiency of zone hospitals in Benin. The African Health Monitor, 12, 30-9. https://doi.org/10.1186/s13561-017-0161-7.

Kounetas, K., \& Papathanassopoulos, F. (2013). How efficient are Greek hospitals? A case study using a double bootstrap DEA approach. The European Journal of Health Economics, 14, 979-994. https://doi.org/10.1007/s10198-012-0446-z

Kruk, M. E., \& Freedman, L. P. (2008). Assessing health system performance in developing countries: a review of the literature. Health Policy (Amsterdam, Netherlands), 85, 263-76. https://doi.org/10.1016/j.healthpol.2007.09.003

Kuwait News Agency. (2016). Finance Minister presents six-point economic reform document to cabinet. The Times. https://www.kuna.net.kw/ArticleDetails.aspx?id=2492530\&Language $=$ en

Lee, K.-S., Chun, K.-H., \& Lee, J.-S. (2008). Reforming the hospital service structure to improve efficiency: urban hospital specialization. Health Policy, 87, 41-49. https://doi.org/10.1016/j.healthpol.2007.10.003

Lee, W.-F., \& Wang, Y.-H. (2004). Technical Efficiency of District Hospitals in Taiwan: Semi-parametric Regression in Second-Stage DEA.

Li, H., \& Dong, S. (2015). Measuring and Benchmarking Technical Efficiency of Public Hospitals in Tianjin, China: A Bootstrap-Data Envelopment Analysis Approach. INQUIRY: The Journal of Health Care Organization, Provision, and Financing. https://doi.org/10.1177/0046958015605487

Lindlbauer, I., Schreyögg, J., \& Winter, V. (2016). Changes in technical efficiency after quality management certification: A DEA approach using difference-in-difference estimation with genetic matching in the hospital industry. European Journal of Operational Research, 250, 1026-1036. https://doi.org/10.1016/j.ejor.2015.10.029

Magnussen, J. (1996). Efficiency measurement and the operationalization of hospital production. Health Services Research, 31, 21.

Mahate, A., Hamidi, S., \& Akinci, F. (2016). Measuring the Effect of Size on Technical Efficiency of the United Arab Emirates Hospitals. Global Journal of Health Science, 9, 58438. https://doi.org/10.5539/gjhs.v9n3p116

Masiye, F. (2007). Investigating health system performance: An application of data envelopment analysis to Zambian hospitals. BMC Health Services Research, 7. https://doi.org/10.1186/1472-6963-7-58

Mills, A. (1995). Improving the efficiency of public sector health services in developing countries: bureaucratic versus market approaches. $37 \mathrm{pp}$. HEFP working paper 01/95

Ministry of Health. (2016). National health accounts: Health expenditure of most important sectors in the State of Kuwait 2011/2012. In: MOH (Ed.) 2nd ed. Kuwait: MOH.

Moshiri, H., Aljunid, S., \& Amin, R. (2010). Hospital efficiency: concept, measurement techniques and review of hospital efficiency studies. Malaysian Journal of Public Health Medicine, 10(2), 35-43. https://doi.org/10.5539/gjhs.v2n2p91

Mujasi, P. N., Asbu, E. Z., \& Puig-Junoy, J. (2016). How efficient are referral hospitals in Uganda? A data envelopment analysis and tobit regression approach. BMC Health Service Research, 16, 230 https://doi.org/10.1186/s12913-016-1472-9

O'Neill, L., Rauner, M., Heidenberger, K., \& Kraus, M. (2008). A cross-national comparison and taxonomy of DEA-based hospital efficiency studies. Socio-Economic Planning Sciences, 42, 158-189. https://doi.org/10.1016/j.seps.2007.03.001

Oikonomou, N., Tountas, Y., Mariolis, A., Souliotis, K., Athanasakis, K., \& Kyriopoulos, J. (2015). Measuring the efficiency of the Greek rural primary health care using a restricted DEA model; the case of southern and western Greece. Health Care Management Science, 19, 313-325. https://doi.org/10.1007/s10729-015-9324-4

Osmani, A. R. (2012). Technical Efficiency of District Hospitals in Afghanistan: A Data Envelopment Analysis Approach. Chulalongkorn University. PSAKU International Journal of Interdisciplinary Research, 1, 82-107. 
https://doi.org/10.12778/235108618X15452373185048

Oxley, H., \& MacFarlan, M. (1994). Health care reform controlling spending and increasing efficiency. OECD Economics Department Working Papers, No. 149. OECD Publishing, Paris, https://doi.org/10.1787/338757855057

Palmer, S., \& Torgerson, D. J. (1999). Definitions of efficiency. $B M J, \quad 318,1136$. https://doi.org/10.1136/bmj.318.7191.1136

Pelone, F., Kringos, D. S., Romaniello, A., Archibugi, M., Salsir, C., \& Ricciardi, W. (2014). Primary Care Efficiency Measurement Using Data Envelopment Analysis: A Systematic Review. Journal of Medical Systems, 39, 156. https://doi.org/10.1007/s10916-014-0156-4

Pérez-Romero C., Ortega-Díaz M. I., Ocaña-Riola R., \& Martín-Martín J. J. (2019). Multilevel analysis of the technical efficiency of hospitals in the Spanish National Health System by property and type of management. Gaceta Sanitaria, 33(4), 325-332. https://doi.org/10.1016/j.gaceta.2018.02.005

Roh, C.-Y., Jae Moon, M., \& Jung, K. (2013). Efficiency Disparities among Community Hospitals in Tennessee: Do Size, Location, Ownership, and Network Matter? Journal of Health Care for the Poor and Underserved, 24, 1816-1833. https://doi.org/10.1353/hpu.2013.0175

Rosko, M. D. (2001). Cost efficiency of US hospitals: a stochastic frontier approach. Health Economics, 10, 539-551. https://doi.org/10.1002/hec.607

Sabah, A. A. S. A. (1962). Kuwait's Constitution. Kuwait: Amir of the State of Kuwait.

Sefiddashti, S. E., Arab, M., Ghazanfari, S., Kazemi, Z., Rezaei, S., \& Karyani, A. K. (2016). Trends of geographic inequalities in the distribution of human resources in healthcare system: the case of Iran. Electronic physician, 8(7), 2607-2613. https://doi.org/10.19082/2607

Siciliani, L. (2006). Estimating Technical Efficiency in the Hospital Sector with Panel Data. Applied Health Economics and Health Policy, 5, 99-116. https://doi.org/10.2165/00148365-200605020-00004

Simar, L., \& Wilson, P. W. (2011). Two-stage DEA: caveat emptor. Journal of Productivity Analysis, 36, 205. https://doi.org/10.1007/s11123-011-0230-6

Smith, P. C., \& Street, A. (2005). Measuring the efficiency of public services: the limits of analysis. Journal of the Royal Statistical Society: Series A (Statistics in Society), 168, 401-417. https://doi.org/10.1111/j.1467-985X.2005.00355.x

Staat, M. (2006). Efficiency of hospitals in Germany: a DEA-bootstrap approach. Applied Economics, 38, 2255-2263. https://doi.org/10.1080/00036840500427502

Tandon, A., Lauer, J. A., Evans, D. B., \& Murray, C. J. (2003). Health system efficiency: Concepts. In C.J. Murray \& D.B. Evans (Eds.), Health systems performance assessment: Debates, methods and empiricism. Geneva, Switzerland: World Health Organization, 683-692.

Tiemann, O., \& Schreyögg, J. (2012). Changes in hospital efficiency after privatization. Health Care Management Science, 15, 310-326. https://doi.org/10.1007/s10729-012-9193-z

Top, M., Konca, M., \& Sapaz, B. (2019). Technical efficiency of healthcare systems in African countries: An application based on data envelopment analysis, Health Policy and Technology. Available online 4 December 2019. https://doi.org/10.1016/j.hlpt.2019.11.010

Tynkkynen, L., \& Vrangbæk, K. (2018). Comparing public and private providers: a scoping review of hospital services in Europe. BMC Health Service Research, 18, 141. https://doi.org/10.1186/s12913-018-2953-9

Watcharasriroj, B., \& Tang, J. C. (2004). The effects of size and information technology on hospital efficiency. The Journal of High Technology Management Research, 15, 1-16. https://doi.org/10.1016/j.hitech.2003.09.001

Worthington, A. C. (2004). Frontier Efficiency Measurement in Health Care: A Review of Empirical Techniques and Selected Applications. Medical Care Research and Review, 61, 135-170. https://doi.org/10.1177/1077558704263796

Wranik, D. (2012). Healthcare policy tools as determinants of health-system efficiency: evidence from the OECD. Health Economics, Policy and Law, 7, 197-226. https://doi.org/10.1017/S1744133111000211

Xenos, P., Nektarios, M., Constantopuolos, A., \& Y fantopuolos, J. (2016). Two-stage hospital efficiency analysis including qualitative evidence: A Greek case. Journal of Hospital Administration, 5, 1. 
https://doi.org/10.5430/jha.v5n3p1

Zere, E., Mbeeli, T., Shangula, K., Mandlhate, C., Mutirua, K., Tjivambi, B., \& Kapenambili, W. (2006). Technical efficiency of district hospitals: evidence from Namibia using data envelopment analysis. Cost Effectiveness and Resource Allocation, 4, 1. https://doi.org/10.1186/1478-7547-4-5

Zhou, L., Xu, X., Antwi, H. A., \& Wang, L. (2017). Towards an equitable healthcare in China: evaluating the productive efficiency of community health centers in Jiangsu Province. Internatonal Journal of Equity in Health, 16, 89. https://doi.org/10.1186/s12939-017-0586-y

\section{Copyrights}

Copyright for this article is retained by the author(s), with first publication rights granted to the journal.

This is an open-access article distributed under the terms and conditions of the Creative Commons Attribution license (http://creativecommons.org/licenses/by/4.0/). 